\title{
General Anesthesia
}

\section{Rapid and complete occlusion of a heat and mois- ture exchange filter by pulmonary edema (Clinical report)}

\author{
[Résumé clinique : occlusion rapide et totale du filtre de l'échangeur de chaleur et \\ d'humidité par de l'adème pulmonaire]
}

David J. Williams FRCA, Mark R.W. Stacey FRCA

Purpose: A case of near fatal obstruction of a breathing system is described, due to occlusion of a heat and moisture exchange filter in a patient with pulmonary edema. Previous reports have described cases of mechanical obstruction to fresh gas flow due to an accumulation of a bolus of fluid within the filter housing. However, in this case, the cause of occlusion was due to the protein and cell debris contained in a small amount of pulmonary edema fluid interacting with the filter membrane.

Clinical features: Obstruction occurred rapidly and without warning, and was difficult to differentiate from the more common diagnoses of bronchospasm or tension pneumothorax. Outwardly the filter appeared normal, and routine protocol for emergency management of suspected breathing system obstruction initially failed to identify the site of occlusion.

Conclusion: Minimal contamination by proteinaceous fluid may cause rapid and complete occlusion of a breathing system filter. Blockage of the breathing system filter and catheter mount should be considered in cases of unexplained breathing system occlusion. The use of a fresh breathing system without a filter for each patient, as recommended by The American Center for Disease Control and the American Society of Anesthesiologists, would have prevented this scenario from occurring.

Objectif : Décrire un cas d'obstruction quasi fatale du système respiratoire causée par l'occlusion du filtre d'un échangeur de chaleur et d'humidité chez un patient atteint d'œdème pulmonaire. Dans les descriptions antérieures, l'obstruction mécanique du débit de gaz frais était causée par l'accumulation d'un bolus de liquide à l'intérieur du boîtier du filtre. Cependant, dans le cas présent, l'occlusion relève de l'interaction de débris protéiques et cellulaires, contenus dans une petite quantité de sérosités pulmonaires, avec la membrane du filtre.

Éléments cliniques : L'obstruction, survenue rapidement et soudainement, a été difficile à distinguer du bronchospasme ou du pneumothorax sous pression plus fréquemment observés. En apparence, le filtre était normal et l'utilisation du protocole régulier d'urgence en cas d'obstruction présumée du système respiratoire n'a pas permis, initialement, de localiser l'occlusion.

Conclusion : La contamination minimale par un liquide protéique peut causer l'occlusion rapide et totale du filtre d'un système respiratoire. Le blocage du montage du cathéter et du filtre de ce système doit être envisagé dans les cas d'occlusion non expliquée. L'utilisation d'un nouveau système respiratoire sans filtre pour chaque patient, comme le recommande The American Center for Disease Control et l'American Society of Anesthesiologists, aurait permis d'éviter cet incident.

Case report

A previously healthy 32 -yr-old woman was admitted for elective radical hysterectomy for cervical carcinoma. Bleeding was difficult to control during the 75 min procedure. On the ward, six hours postoperatively, she was noted to have a blood pressure of $70 / 40$ and heart rate of 110 beats. $\mathrm{min}^{-1}$. Full blood count revealed a hemoglobin concentration of $4.5 \mathrm{~g} \cdot \mathrm{L}^{-1}$. Oxygen was administered via a face mask and reservoir bag, and further $i v$ access was secured with two $14 \mathrm{~g}$

From the Department of Anaesthesia and Intensive Care, University Hospital of Wales, Heath Park, Cardiff, United Kingdom. Address correspondence to: Dr. David J. Williams, Department of Anaesthesia and Intensive Care, University Hospital of Wales, Heath Park, Cardiff CFl4 4XW, United Kingdom. Phone: 442920 743107; Fax: 442920 745489; E-mail: davidjwilliams@doctors.org.uk Accepted for publication July 25, 2001.

Revision accepted September 17, 2001. 
cannulae. She was immediately transferred to the operating room with blood transfusion in progress.

Induction of anesthesia was uneventful. A circle system was used, with a heat and moisture exchange filter (HMEF; Model BB25, PALL Biomedical, Portsmouth, UK) between the Y piece of the circle system and the catheter mount, as recommended by the manufacturer. Anesthesia was maintained with isoflurane $0-1 \%$ in $99 \%$ oxygen, with intermittent boluses of rocuronium and opioids as required.

Identifying and controlling the source of the bleeding proved to be difficult, and despite $45 \mathrm{~min}$ of aggressive fluid resuscitation with blood and colloid via a fluid warmer and pressure infuser, she remained anuric and became increasingly tachycardic and hypotensive. Invasive monitoring was instituted via a radial arterial cannula and a triple lumen central venous cannula (CVC). Both were inserted easily. Five minutes after CVC insertion, ventilation of the patient became increasingly difficult. The ventilation pressure alarm sounded, and an inspiratory airway pressure of $50 \mathrm{~cm}$ $\mathrm{H}_{2} \mathrm{O}$ was noted. Oxygen saturation was impossible to interpret due to peripheral vasoconstriction and profound anemia. However, an arterial blood gas sample taken at this time showed $\mathrm{SpO}_{2} 66 \%, \mathrm{PO}_{2} 33.5 \mathrm{mmHg}$, $\mathrm{PCO}_{2} 48.5 \mathrm{mmHg}$, pH 7.06.

The patient's lungs were ventilated by hand, which confirmed a marked decrease in compliance. The circle system was disconnected from the filter and found to be functioning normally, thereby excluding mechanical obstruction upstream of the filter as a cause of raised inspiratory airway pressure. A suction catheter was passed down the tracheal tube. Pulmonary edema fluid was removed, but the tube was not obstructed. On auscultation of the chest, bilaterally, very quiet breath sounds were heard with widespread coarse crepitations and no audible wheezes. Airway pressures continued to rise in excess of $60 \mathrm{~cm} \mathrm{H} \mathrm{H}_{2} \mathrm{O}$, with tidal volumes of only $20-30 \mathrm{~mL}$; central venous pressure increased to over $20 \mathrm{~cm} \mathrm{H}_{2} \mathrm{O}$ and blood pressure decreased to less than $50 \mathrm{mmHg}$ systolic. Pulmonary edema fluid was noted in the tracheal tube. Despite easy insertion of the CVC and the presence of breath sounds, the possibility of an iatrogenic tension pneumothorax was considered, and preparations were made for bilateral chest tube insertion. Despite a normal external appearance of the PALL BB25 filter, it was changed for a new larger model (Model BB22-15M, PALL Biomedical, Portsmouth, UK). Ventilation immediately became easier, and compliance and airway pressures returned to normal. During the course of the remaining $45 \mathrm{~min}$ of anesthesia, the filter was changed another three times. On each occasion, airway pressures dropped by $10 \mathrm{~cm} \mathrm{H}_{2} \mathrm{O}$. It was surmised that a small amount of pulmonary edema fluid had interacted with the filtration membrane of the HMEF, rendering it completely impermeable to gas flow.

The pulmonary edema was treated by returning the patient to the horizontal position, repeated suction, inverse ratio ventilation with $15 \mathrm{~cm}$ positive end-expiratory pressure (PEEP) and iv furosemide $225 \mathrm{mg}$. Short-term ionotrope support with epinephine and dobutamine was required.

The source of the bleeding was eventually controlled with the aid of pelvic packs. Total perioperative blood loss was in excess of $8 \mathrm{~L}$. The patient was transferred to the intensive therapy unit for controlled ventilation overnight, and extubated the following day. There were no neurological sequelae. She returned to the operating room $48 \mathrm{hr}$ later for removal of the pelvic packs, which proceeded uneventfully, and was discharged from hospital three days later.

\section{Investigations}

Occlusion of the filter was illustrated by attaching it to a Mapleson C circuit (Figure 1). Pressure testing in accordance with European standards ${ }^{1}$ showed that even when dry, seven days after the critical incident, the filter membrane remained completely impermeable to gas, and only ruptured when subjected to a pressure of $125 \mathrm{~cm} \mathrm{H}_{2} \mathrm{O}$.

Attempts were made to reproduce the scenario in vitro by saturating fresh filters with a range of fluids. Saline, gelofusine and albumin solutions were rapidly repelled by the hydrophobic membrane and did not cause any increase in resistance to gas flow.

Scanning electron micrographs of the original filter material showed that the patient side of the filter membrane was completely occluded by a mixture of proteinaceous exudate and cell debris (Figure 2).

The exudate was eluted with methanol and analyzed with a mass spectrometer, which demonstrated high concentrations of the plasticiser 1,2-Benzenedicarboxylic acid diisooctyl ester; a harmless contaminant that probably originated from components of the breathing system. No other compounds were demonstrated.

Samples of the filter membrane along with details of the incident were sent to the manufacturer for comment and further investigation.

\section{Discussion}

The HMEF is a type of breathing system filter (BSF) composed of a single pleated sheet of hydrophobic resin- bonded ceramic filaments, which filters microorganisms and also acts as a condenser humidifier. ${ }^{1}$ 


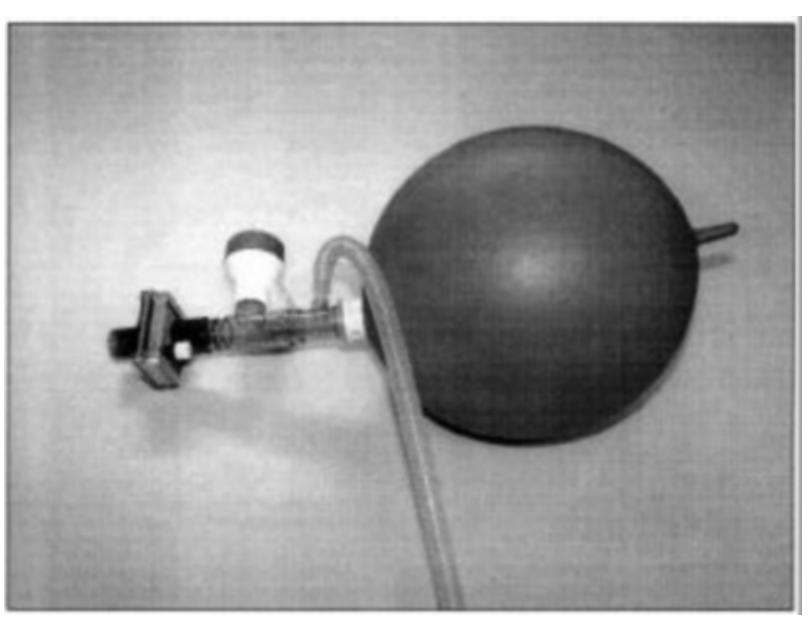

FIGURE 1 The heat and moisture exchange filter (HMEF) connected to a Mapleson C system, illustrating the complete blockage to gas flow.

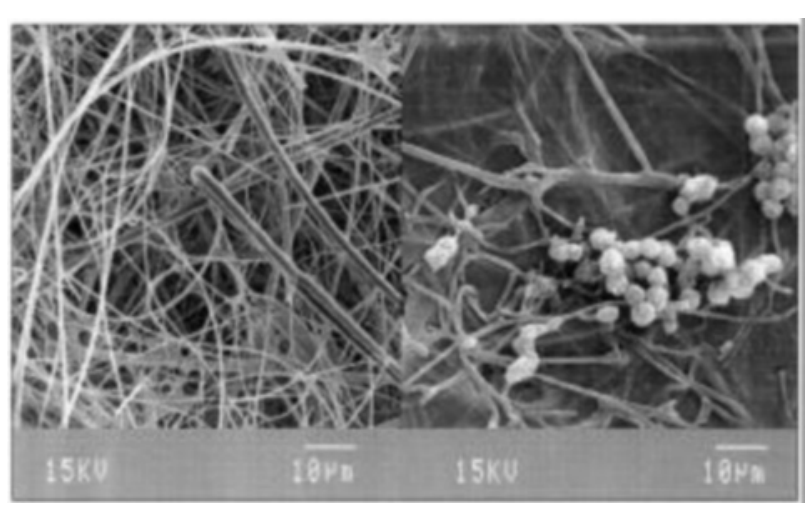

FIGURE 2 Electron micrographs of a normal heat and moisture exchange filter (HMEF) membrane (left), and the HMEF membrane after exposure to pulmonary edema fluid (right) showing occlusion of pores by secretions and cell debris.

However, studies have shown that use of HMEFs does not lead to a reduction in postoperative morbidity. ${ }^{2}$ Transmission of nosocomial infection via the breathing system of an anesthetic machine has not been proven conclusively, ${ }^{3}$ and HMEF may be unsatisfactory in providing a barrier to certain pathogens, including the hepatitis $\mathrm{C}$ virus. ${ }^{4}$ Equipment dead-space and breathing resistance are increased, which may cause rebreathing and increased work of breathing. ${ }^{1}$

A number of critical incidents involving occlusion of HMEF and BSF have been reported. Filter occlu- sion may be due to a foreign body within the device, ${ }^{5-9}$ accumulation of condensed water within the device causing a physical obstruction to gas flow, ${ }^{10}$ or contaminants interacting with the filter membrane to cause pore occlusion. Contaminants include nebulised salbutamol, ${ }^{11}$ nebulised ipratropium bromide, ${ }^{12} \mathrm{spu}-$ tum, ${ }^{13}$ mucus combined with nebulised n-acetylcysteine, ${ }^{14}$ blood from pulmonary contusion ${ }^{15}$ and pulmonary edema. ${ }^{16}$ Blockage of a device in the inspiratory limb or Y-connector of a circle system may prevent ventilation of the patient, mimicking airway occlusion; blockage of a device in the expiratory limb may prevent expiration, causing raised airway pressures and bilateral tension pneumothorax..$^{8,13}$

The BB25 HMEF is contraindicated for use with nebulisers, and the manufacturers advise removal of the device if the patient produces blood or exudates which enter the filter; ${ }^{17}$ however, contamination may be impossible to predict, and the consequences may be rapidly fatal. In this instance, the initial blockage caused complete inability to ventilate the patient. Repeated replacement of HMEFs was required to maintain normal airway pressures.

Unlike other filters, which rupture at pressures of $<15 \mathrm{~cm} \mathrm{H}_{2} \mathrm{O}$ if pore occlusion occurs, integrity of the HMEF membrane is maintained at pressures $>70 \mathrm{~cm}$ $\mathrm{H}_{2} \mathrm{O}^{18}$ significantly greater than pressures encountered in clinical practice. This is a "fail-unsafe" design, in which an antibacterial barrier is maintained at the expense of the ability to ventilate the patient. ${ }^{19}$

The American Center for Disease Control (CDC) advocate the use of a fresh sterile breathing system for each patient, and states that there is "no recommendation for placing a bacterial filter in the breathing system or patient circuit of anesthetic equipment". ${ }^{20}$ These views are endorsed by the American Society of Anesthesiologists (ASA). ${ }^{21}$ In contrast, The Association of Anaesthetists of Great Britain and Ireland recommend that the same breathing system be used for multiple patients (except in cases of high infection risk), with a fresh BSF between the catheter mount and breathing circuit for each patient to protect both the patient and the anesthetic circuit from potential bacterial and viral cross-contamination. ${ }^{22}$ The use of a breathing system without a filter, as recommended by CDC and ASA, would have prevented this scenario from occurring.

The etiology of the pulmonary edema in this patient is not certain, but may have been due to low pressure associated with hypotension and massive transfusion. This was not a case of negative pressure pulmonary edema, as the patient was fully paralyzed (as confirmed by a normal respiratory pattern, capno- 
graph waveform, and absent train-of-four response to peripheral nerve stimulation), and thus unable to make spontaneous efforts to breathe against an occluded breathing system.

A combination of factors caused delay in the diagnosis. The scenario was not familiar and mimicked the more common differential diagnoses of tension pneumothorax, severe bronchospasm or tracheal tube occlusion. There was minimal fluid contamination within the HMEF housing, and this was not immediately apparent on inspection. In accordance with our protocol for emergency management of suspected breathing system obstruction, the catheter mount was disconnected from the endotracheal tube, and a suction catheter was passed down the endotracheal tube to confirm tube patency, eliminating a cause for obstruction at the "patient end". The breathing system upstream of the filter was completely replaced to eliminate a cause of mechanical obstruction at the "machine end". Unfortunately, as this case illustrates strikingly, the breathing system filter and catheter mount lie in a watershed area between the "patient end" and the "machine end"; and may be overlooked initially.

It is proposed to raise awareness of this scenario by incorporating it into anesthetic critical incident simulators.

Conclusions

It is believed that the protein contained within the small amount of pulmonary edema fluid interacted with the hydrophobic membrane of the HMEF, rendering it completely impermeable to gas flow. This experience reinforces the advice of other authors to consider partial occlusion of the HMEF in cases of unexplained PEEP or cardiovascular instability ${ }^{1}$ and to avoid the use of HMEF in patients with pulmonary hemorrhage or edema. ${ }^{16,17}$ It also supports the advice of the CDC and ASA that routine use of a bacterial filter between the Y piece and endotracheal tube is not recommended.

Acknowledgements

The authors wish to thank Tony Wilkes and Mark Hampson of the Medical Devices Evaluation Unit; Neil Willis and Doug Proctor of the Department of Medical Biochemistry; and Dr. Geoff Newman and Chris von Ruhland of the Medical Microscopy Unit; University Hospital of Wales, Heath Park, Cardiff CF14 4XN, UK.

\section{References}

1 Wilkes AR Heat and moisture exchangers. Structure and function. Respir Care Clin N Am 1998; 4: 261-79.
2 Hayes B. Humidification in anaesthesia (Editorial). Br J Anaesth 1979; 51: 389-90.

3 du Moulin GC, Hedley-White J. Bacterial interactions between anesthesiologists, their patients, and equipment. Anesthesiology 1982; 57: 37-41.

4 Lloyd G, Howells J, Liddle C, Klineberg PL. Barriers to hepatitis $\mathrm{C}$ transmission within breathing systems: efficacy of a pleated hydrophobic filter. Anaesth Intensive Care 1997; 25: 235-8.

5 Casta A, Houck C. Acute intraoperative endotracheal tube obstruction associated with a heat and moisture exchange in an infant (Letter). Anesth Analg 1997; 84: 938-9.

6 Koga $\Upsilon$, Iwatsuki N, Takahashi M, Hashimoto $\Upsilon$. A hazardous defect in a humidifier (Letter). Anesth Analg 1990; 71: 708-13.

7 Prados $W$. A dangerous defect in a heat and moisture exchanger (Letter). Anesthesiology 1989; 71: 804.

8 Smith CE, Otworth JR, Kaluszyk P. Bilateral tension pneumothorax due to a defective anesthesia breathing circuit filter. J Clin Anesth 1991; 3: 229-34.

9 Aarhus D, Søreide E, Holst-Larsen H. Mechanical obstruction in the anaesthesia delivery-system mimicking severe bronchospasm. Anaesthesia 1997; 52: 989-97.

10 Buckley PM. Increase in resistance of in-line breathing filters in humidified air. Br J Anaesth 1984; 56: 637-43.

11 Barton RM. Detection of expiratory antibacterial filter occlusion (Letter). Anesth Analg 1993; 77: 197-201.

12 Department of health and social security. Pall Ultipor breathing system filter (BB50/BB50T/BB22-15): warning on the use of ipratropium bromide (atrovent). Health notice HN (HAZARD)(85)7, July 1985.

13 McEwan AI, Dowell L, Karis JH. Bilateral tension pneumothorax caused by a blocked bacterial filter in an anesthesia breathing circuit. Anesth Analg 1993; 76 : 440-2.

14 Stacey MRW, Asai T, Wilkes A, Hodzovic I. Obstruction of a breathing system filter (Letter). Can J Anaesth 1996; 43: 1276.

15 Mason J, Tackley R. An acute rise in expiratory resistance due to a blocked ventilator filter (Letter). Anaesthesia 1981; 36: 335.

16 Kopman AF, Glaser L. Obstruction of bacterial filters by edema fluid. Anesthesiology 1976; 44: 169-70.

17 Pall Biomedical Products Co. BB25/BB25F Pall breathing system filter. Product information leaflet; New York, USA.

18 Lee MG, Ford JL, Hunt PB, Ireland DS, Swanson PW. Bacterial retention properties of heat and moisture exchange filters. Br J Anaesth 1992; 69: 522-5.

19 Wilkes $A$. Resistance to gas flow in heat and moisture 
exchangers (Letter). Anaesthesia 1992; 47: 1095-6.

20 American Center for Disease Control (CDC) MMWR; 1997; 46(RR-1): 1-79.

21 American Society of Anesthesiologists. Recommendations for Infection Control for the Practice of Anesthesiology, 2nd ed. Park Ridge: Illinois, 1998.

22 Association of Anaesthetists of Great Britain and Ireland. A report received by council of the Association of Anaesthetists on blood bourne viruses and anaesthesia. An update. January 1996.

\section{APPENDIX}

We agree with the authors' conclusion that users should consider partial occlusion of a breathing circuit filter in cases of unexplained positive end-expiratory pressure (PEEP) or cardiovascular instability. However, the use of these devices need not be avoided in patients with pulmonary hemorrhage or edema if the information specified in the product's instructions for use is followed. Review of these instructions, in conjunction with clinical judgement by the attending anesthesiologist, is required in order to determine the suitability of the device for the situation at hand.

Pulmonary edema fluid often contains surfactants which may penetrate the pores of any breathing circuit filter media. However, the Pall BB25 filter and Pall BB22-15M filters, that were used in this instance, have pleated hydrophobic filter membranes with surface areas of approximately $240 \mathrm{~cm}^{2}$ and $700 \mathrm{~cm}^{2}$ respectively. A recent article has shown that breathing circuit filters which incorporate only a pleated hydrophobic filter membrane are less likely to block or cause excessive work of breathing as a result of occult accumulation of patient secretions than composite breathing circuit filters. ${ }^{1}$

The instructions for use for Pall breathing circuit filters contains information concerning clinical management of patients who produce secretions. We would urge users to ensure that, prior to using a medical device, they read and familiarize themselves with the product's instructions for use. Furthermore, vigilance should be maintained at all times, during use of breathing circuit filters, so that, although rare, if an increase in airway pressure does occur the filter can be immediately removed. Also, as specified in the product's instructions for use, ventilator pressure alarms should be in use at all times. In the instance described in this case report it is mentioned that a catheter mount was used between the patient's endotracheal tube and the filter. Therefore one would have expected that any pulmonary edema would have initially collected there and given prior indication of the potential problem. Furthermore positioning of the breathing circuit filter above the level of the endotracheal tube will also reduce the likelihood of fluid collecting in the filter housing.

Cross contamination via anesthetic breathing circuits has been documented. ${ }^{2}$ It has also been shown that different types of breathing circuit filters have differing abilities to reliably retain airborne and liquidborne contaminants. ${ }^{3}$ However, Pall breathing circuit filters have been validated to remove a range of indicator organisms and clinically relevant pathogens including staphyloccocus aureus, ${ }^{4}$ mycobacterium tuberculosis, ${ }^{5}$ human immunodeficiency virus $^{6}$ and hepatitis $\mathrm{C}$ virus. ${ }^{7}$

Consequently Pall breathing circuit filters are used widely to prevent cross infection via breathing systems in anesthesia. Several million Pall breathing circuit filters are used each year for this purpose. From over 15 years of clinical experience we can confirm that reports of increased resistance during use of these products are extremely rare and are generally related to the product's instructions for use not being adhered to. The rarity of this type of occurrence means that, when an unfortunate instance of increased filter resistance in anesthesia does occur, it attracts the attention of healthcare professionals. We would therefore agree with the author's proposal that awareness of this type of scenario should be raised by including filters and/or HMEs exhibiting increased resistance in anesthetic critical incident simulators.

John A. Roe PhD

Pall Life Sciences

Portsmouth, UK

Leonard S. Berman PhD

Pall Corporation

New York, USA

\section{References}

1 Morgan-Hughes NJ, Mills GH, Northwood D Air flow resistance of three heat and moisture exchanging filter designs under wet conditions: implications for patient safety. Br J Anaesth 2001; 87: 289-91.

2 Heinsen A, Bendtsen F, Fomsgaard A A phylogenetic analysis elucidating a case of patient-to-patient transmission of hepatitis $\mathrm{C}$ virus during surgery. J Hosp Infect 2000; 46: 309-13.

3 Hedley RM, Allt-Graham J. A comparison of the filtration properties of heat and moisture exchangers. Anaesthesia 1992; 47: 414-20.

4 Rosales $M$, Dominguez $V$. In vitro ability of HME filters to protect intubated patients against bacterial contamination. 2nd Int Conf Infect Prevent, Nice, France 4-5 May 1992.

5 Speight S, Bennett AM, Lever MR, Benbough J. Efficacy 
of a pleated hydrophobic filter as a barrier to mycobacterium tuberculosis transmission within breathing systems. Centre for Applied Microbiology and Research (CAMR) 1995.

6 Lloyd G, Howells J. Efficacy of a pleated hydrophobic filter as a barrier to human immunodeficiency virus transmission within breathing systems. Centre for Applied Microbiology and Research (CAMR) 1995.

7 Lloyd G, Howells J, Liddle C, Klineberg PL. Barriers to hepatitis $\mathrm{C}$ transmission within breathing systems: efficacy of a pleated hydrophobic filter. Anaesth Intensive Care 1997; 25: 235-8.

\section{History of Canadian Anestbesia}

\section{Werner Kalow's Contributions to Pharmacogenetics}

Sixty years ago Ralph Waters said that our patients have sometimes not benefited because we have been slow to apply "demonstrated facts." The recent award of a Canada Council for the Arts Killam prize to Dr. Werner Kalow, brings to mind his achievements in pharmacogenetics and their importance for anesthesiology - and indicates that Dr. Waters' observation is not true in this instance. Dr. Kalow is an example of a medical scientist whose work has refined both the science and art of anesthesia. His discoveries include the genetic variation of plasma cholinestcrase (1956) and the pharmacodiagnosis of malignant hyperthermia using caffeine (1979). The significance of Dr. Kalow's work for anesthesiology was recognized when the Canadian Anesthesiologists' Society appointed him Royal College Lecturer in 1980 and presented him with the CAS Reasearch Recognition Award in 1993. The significance of Dr. Kalow's studies, however, goes far beyond anesthesiology, for he has shown how the broad field of pharmacobiology, through its analysis of drug effects, is capable of solving profound biological problems. The nature of such problems is reviewed by two recent articles by Dr. Kalow: "Pharmacogenetics in perspective" (Drug Metabolism and Disposition 2001; 29: 468-70), and "Pharmacogenetics, pharmacogenomics, and pharmacobiology" (Clinical Pharmacology \& Therapentics 2001; 70: 1-4).

David Shephard MD Charlottetown, PEI

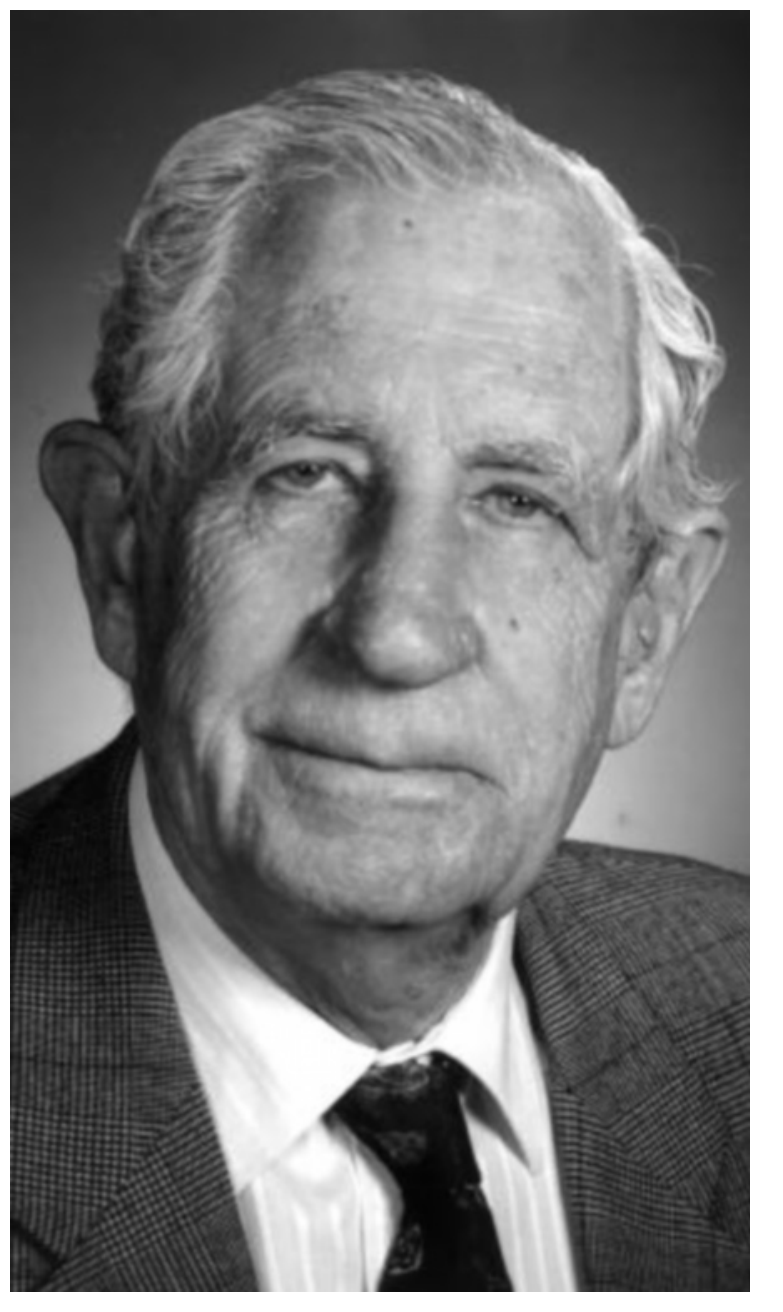

